\title{
Treatment of squamous cell carcinoma of the anal canal: A new strategies with anti-EGFR therapy and immunotherapy
}

\author{
A. Casadei Gardini ${ }^{\mathrm{a}, *}$, A. Passardi ${ }^{\mathrm{a}}$, L. Fornaro ${ }^{\mathrm{b}}$, P. Rosetti $^{\mathrm{b}}$, M. Valgiusti ${ }^{\mathrm{a}}$, S. Ruscelli ${ }^{\mathrm{a}}$, M. Monti $^{\mathrm{a}}$, \\ C. Casadei ${ }^{\mathrm{a}}$, F. Pagan ${ }^{\text {c }}$, G.L. Frassineti ${ }^{\mathrm{a}}$ \\ a Department of Medical Oncology, Istituto Scientifico Romagnolo per lo Studio e Cura dei Tumori (IRST) IRCCS, Via Maroncelli, 40, 47014 Meldola, Italy \\ ${ }^{\mathrm{b}}$ Medical Oncology 2, Azienda Ospedaliero-Universitaria Pisana, University of Pisa, Pisa, Italy \\ ${ }^{\mathrm{c}}$ Unit of Biostatistics and Clinical Trials, Istituto Scientifico Romagnolo per lo Studio e Cura dei Tumori (IRST) IRCCS, Via P. Maroncelli, 40, 47014, Meldola, Italy
}

\section{A R T I C L E I N F O}

\section{Keywords:}

Anal cancer

Immunotherapy

Nivolumab

Anti-EGFR

Cetuximab

Pembrolizumab

Panitumumab

\begin{abstract}
A B S T R A C T
The incidence of squamous cell carcinoma of the anal canal (SCAC) is increasing in both sexes but the standard treatment remains that of 20 years ago. However, interesting data have recently emerged on the use of antiepidermal growth factor receptor (EGFR) agents and immunotherapy in advanced disease. Thus, new avenues of research are opening up that will hopefully lead to more effective therapeutic strategies. We provide an overview of the latest studies published on this tumor and discuss the possible future therapeutic options for combination therapy, anti-EGFR treatment and radiotherapy.
\end{abstract}

\section{Introduction}

Squamous cell carcinoma of the anal canal (SCAC) represents $2.5 \%$ of all gastrointestinal cancers. However, the incidence of this tumor is gradually increasing in both sexes due to infection from human papilloma virus (HPV) (Altekruse et al., 1975). Five-year survival is $80 \%$ for localized disease (Johnson et al., 2004). In the past, abdominoperineal resection and permanent colostomy was the standard therapy for non-metastatic disease and 5-year survival was 50-60\% (Clark et al., 2004). In 1974 Nigro et al. (1974) reported a complete response (CR) in 3 patients treated with a combination of radiation therapy and chemotherapy (mitomycin C and 5-fluorouracil [5-FU]). However, no phase III randomized trials comparing abdominoperineal resection with radiochemotherapy have been conducted to date. Furthermore, there are virtually no data in the literature on the treatment of metastatic SCAC, the current standard of care for which is cisplatin and 5-FU (Faivre et al., 1999; Jaiyesimi and Cisplatin, 1993; Tanum, 1993; Khater et al., 1986; Ajani et al., 1989). The overall response rate is $60 \%$, with a median survival of 12 months. As with localized disease, treatment for advanced disease has not changed in the last 20 years. However, several interesting studies have been published in this area over the past 12 months. The present review evaluates the latest data published on SCAC and discusses the future therapeutic options for combination therapy, anti-EGFR treatment and radiotherapy.

\section{Role of anti-EGFR therapy in the treatment of SCAC}

Epidermal growth factor receptor (EGFR) is overexpressed in about $90 \%$ of SCAC, whereas KRAS and NRAS mutations are rare (Capelli et al., 2016; Casadei Gardini et al., 2014; Zampino et al., 2009; Cacheux et al., 2016). PIK3CA is mutated in $20 \%$ of patients (Capelli et al., 2016). These observations provide a theoretical rationale for integrating anti-EGFR agents into standard treatment for SCAC. Fig. 1 summarizes the chemoradiotherapy schedules of the most important studies carried out to date and Table 1 reports the main results obtained. In 2013, Olivatto et al. were the first to evaluate the use of cetuximab (Olivatto et al., 2013) in a phase I study in which cetuximab was administered with cisplatin and 5-FU in concomitance with radiotherapy. The study was closed due to challenging safety results. All 23 patients enrolled experienced grade $3 / 4$ toxicity (100\%): radiation dermatitis in $52.1 \%$ of cases, diarrhea in $43.4 \%$, thrombosis and embolism in $26 \%$ and infection in $21 \%$. With regard to efficacy, encouraging results were reported, with $95 \%$ of patients achieving a pathological CR and a 3-year locoregional control rate of $64.2 \%$. In the same year, Deutsch et al. published the results of the UNICANCER ACCORD 16 phase II trial (Deutsch et al., 2013) in which the same regimen was used to treat 16 patients. However, the study was prematurely closed because of severe toxicity in $88 \%$ of the population. With regard to efficacy, $55 \%$ of patients showed a CR and $45 \%$ a partial response (PR). Median objective response duration was 14.7 months.

\footnotetext{
* Corresponding author.

E-mail address: andrea.casadei@irst.emr.it (A. Casadei Gardini).
} 


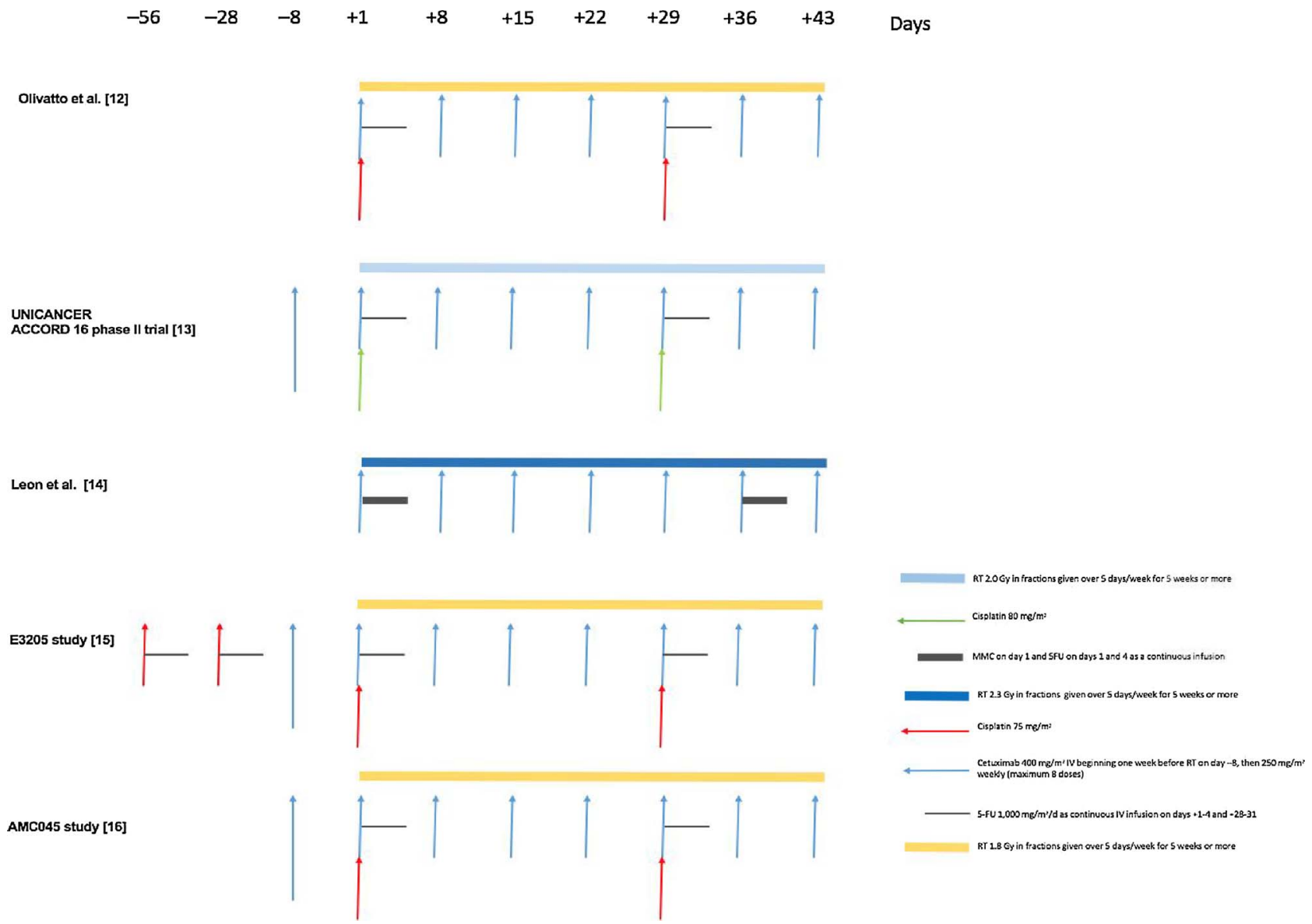

Fig. 1. Treatment scheme of the most important studies on SCAC. 5-FU, 5-fluorouracil; IV, intravenous; RT, radiation therapy; MMC, mitomycin C.

Table 1

Results from the most relevant studies with anti-EGFR antibodies on SCAC.

\begin{tabular}{|c|c|c|c|c|c|c|c|c|c|}
\hline & $\begin{array}{l}\text { Grade } 3 / 4 \\
\text { adverse event } \\
\%\end{array}$ & $\begin{array}{l}\text { Treatment- } \\
\text { related death\% }\end{array}$ & $\begin{array}{l}\text { Median objective } \\
\text { response } \\
\text { (months) }\end{array}$ & $\begin{array}{l}\text { One-year } \\
\text { colostomy-free } \\
\text { survival } \%\end{array}$ & $\begin{array}{l}\text { Complete } \\
\text { response } \%\end{array}$ & $\begin{array}{l}\text { Partial } \\
\text { response\% }\end{array}$ & $\begin{array}{l}\text { Locoregional control } \\
\text { rate (2-year) ( } 3 \text {-year) \% }\end{array}$ & $\begin{array}{l}\text { PFS }(1- \\
\text { year) }(3- \\
\text { year) } \%\end{array}$ & $\begin{array}{l}\text { OS (1-year) } \\
(2 \text {-year) }(3- \\
\text { year) } \%\end{array}$ \\
\hline $\begin{array}{l}\text { Olivatto } \\
\text { et al. }\end{array}$ & 86 & NA & NA & NA & 95 & NA & $\begin{array}{l}\text { (NA) } \\
(64.2)\end{array}$ & $\begin{array}{l}\text { (NA) } \\
\text { (NA) }\end{array}$ & $\begin{array}{l}\text { (NA) } \\
\text { (NA) } \\
\text { (NA) }\end{array}$ \\
\hline $\begin{array}{l}\text { Deutsch } \\
\text { et al. }\end{array}$ & 88 & 0 & 14.7 & 67 & 55 & 45 & $\begin{array}{l}\text { (NA) } \\
\text { (NA) }\end{array}$ & $\begin{array}{l}(62) \\
(\mathrm{NA})\end{array}$ & $\begin{array}{l}\text { (92) } \\
\text { (NA) } \\
\text { (NA) }\end{array}$ \\
\hline Leon et al. & 81.8 & 0 & NA & NA & 91 & NA & $\begin{array}{l}(73) \\
\text { (NA) }\end{array}$ & $\begin{array}{l}\text { (NA) } \\
\text { (NA) }\end{array}$ & $\begin{array}{l}\text { (NA) } \\
(88) \\
\text { (NA) }\end{array}$ \\
\hline E3205 study & 32 & 5 & NA & NA & 59 & NA & $\begin{array}{l}\text { (NA) } \\
(77)\end{array}$ & $\begin{array}{l}(\mathrm{NA}) \\
(68)\end{array}$ & $\begin{array}{l}\text { (NA) } \\
\text { (NA) } \\
(83)\end{array}$ \\
\hline $\begin{array}{r}\text { AMC045 } \\
\text { study }\end{array}$ & 26 & 4.4 & NA & NA & 62 & 5 & $\begin{array}{l}\text { (NA) } \\
(58)\end{array}$ & $\begin{array}{l}\text { (NA) } \\
(72)\end{array}$ & $\begin{array}{l}\text { (NA) } \\
\text { (NA) } \\
\text { (79) }\end{array}$ \\
\hline
\end{tabular}

SCAC, squamous cell carcinoma of the anal canal; PFS, progression-free survival; OS, overall survival; NA, not available.

$38 \%$ of patients relapsed after a median follow-up of 22 months. Oneyear colostomy-free survival was $67 \%$, one year progression-free survival (PFS) was $62 \%$ and one-year overall survival (OS) was $92 \%$.

In 2015, Leon et al. (2015) published their findings of a phase I study evaluating cetuximab, mitomycin $\mathrm{C}$ and 5-FU in concomitance with radiotherapy. Thirteen patients were enrolled. The most common grade 3 and 4 side-effects were radiation dermatitis in $63 \%$ of patients, hematologic toxicity in $54 \%$ and diarrhea in $36 \%$. No treatment-related deaths were recorded. Estimated 2-year relapse-free survival (RFS) and OS was $73 \%$ and $88 \%$, respectively.

The results from the phase II E3205 study (Garg et al., 2017) were published in March 2017. Patients received cetuximab, cisplatin and 5$\mathrm{FU}$ at the same dosages as those of the aforementioned studies. Of the 61 patients enrolled, $19(32 \%)$ had grade 4 toxicity and $3(5 \%)$ died 
from treatment-related causes. The objective response rate was $65 \%$. $15 \%$ of patients had locoregional recurrence after 3 years. The findings of the AMC045 trial (Sparano et al., 2017) were published around the same time. Forty-five HIV-positive patients were enrolled onto the study: grade 4 toxicity occurred in $12(26 \%)$ cases and there were 2 (4\%) treatment-associated deaths. The 3-year locoregional failure rate was $42 \%$, 3-year PFS was $72 \%$ and 3 -year OS was $79 \%$. The locoregional failure rate was nonetheless low when compared with historical data. There were, however, several differences between the two study populations. In the AMC045 study the mean age was lower (47 years), more than $70 \%$ of patients had initial-stage disease (cT1 or T2) and the majority received modulated intensity (IMRT) radiotherapy, resulting in lower toxicity. However, the toxicity observed, especially in terms of the percentage of toxic deaths, was unacceptable in this patient setting.

There are very few data available on advanced SCAC. In 2009 Lukan et al. (Lukan et al., 2009) published the results of a study on 7 patients treated with cetuximab. The 2 patients with KRAS-mutated tumors progressed, whereas among the 5 patients with KRAS wild type disease, 3 had a partial remission, one had a minor remission and one progressed. In 2016, Rogers et al. (2016) published a retrospective study on 17 SCAC patients treated with cetuximab or panitumumab, $35 \%$ of whom achieved a CR and 24\% stable disease (SD). Median PFS and OS were 7.3 and 24.7 months, respectively. Recently, Kim et al. (2017) published results from a retrospective study on 13 patients treated with anti-EGFR therapy alone or in combination with chemotherapy. Data confirmed good efficacy (the disease control rate was $46.2 \%$ ) with acceptable PFS and OS (4.4 months and 11.4 months, respectively). Finally, several case reports have also been published suggesting the potential clinical activity of cetuximab in this setting (Barmettler et al., 2012; Rogers et al., 2015). The promising findings obtained could form the basis for the use of anti-EGFR agents in future phase II or III studies on advanced SCAC.

\section{Role of immunotherapy in the treatment of metastatic SCAC}

Immunosuppression is a risk factor for SCAC development (Nelson, 2017) and predisposes the anal epithelium to human papillomavirus (HPV) infection and its persistence. Affecting around 95\% of patients with metastatic SCAC, the virus integrates into the host cell DNA and promotes oncogenesis (Capelli et al., 2016). It has been demonstrated that HPV increases the risk of cancer of the head and neck, uterine cervix, penis and vulva (Faivre et al., 1999; Jaiyesimi and Cisplatin, 1993). HPV-16 subtypes are the most common in SCAC patients. HPVassociated oncogenesis is caused by viral DNA oncoproteins. These nonself proteins, which are present within tumor cells, could play a potentially important role in the rationale of emerging targeted immunotherapies for SCAC. Table 2 reports the main results obtained with immunotherapy to date.

A retrospective study (Gujja et al., 2015) of 41 patients with SCAC reported a prevalence of programmed death-ligand 1 (PD-L1) expression of $56 \%$. No significant differences in survival were noted between patients with varying levels of PD-L1 expression. The KEYNOTE-028 study conducted by Ott et al. (2017) enrolled 43 patients, 32 of whom were PDL-1 positive. All patients had undergone treatment with other lines of chemotherapy before entering the study. Twenty-five patients underwent treatment with pembrolizumab at the dose of $10 \mathrm{mg} / \mathrm{kg}$ once every 2 weeks. $65 \%$ experienced adverse events, only $16 \%$ of which were grade 3 and 4 . The overall response rate was $17 \%$ and another $42 \%$ of patients obtained SD. Median PFS was 3.0 months and median OS was 9.3 months.

In the recent study by Morris et al. (2017) on the use of nivolumab in SCAC, the majority of the 37 patients enrolled had previously received at least two lines of treatment. $24 \%$ of patients responded (7 PR and $2 \mathrm{CR}$ ), with a durable response (median duration 5.8 months). The median reduction in the number of target lesions from baseline for responders was $70 \%$, an interesting result considering that this was third-line treatment. Median PFS was 4.1 months and median OS was 11.5 months, with an estimated one-year overall survival of $48 \%$.

SCAC occurs frequently in patients with human immunodeficiency virus (HIV) (Capelli et al., 2016). Yanik et al. reported that HIV status did not correlate with the degree or composition of PD-L1 expression in the tumor (Yanik et al., 2017), suggesting that anti-PD-1/PD-L1 drugs could be used, regardless of HIV status. Of the 2 HIV-positive patients enrolled in Morris' study on nivolumab, neither experienced grade 3 or 4 adverse events and one showed a PR.

\section{Combination of anti-EGFR therapy, immunotherapy and/or radiotherapy}

Therapeutic monoclonal antibodies consist of two fragments: antigen-binding fragments (Fab) and a crystallizable fragment (Fc). Fab fragments bind tumor antigens, while the Fc fragment mediates the binding and activation of immune cells. Cetuximab influences the immune response via 2 interactions: 1) Fab binds its target and the first component of complement (C1q) to Fc fragments, leading to the activation of the classic complement pathway (Gancz and Fishelson, 2009); and 2) tumor cells and bound antibodies are recognized by natural killer (NK) cells, resulting in the activation of NK cells and cytotoxic Tlymphocytes and subsequently in damage to the tumor cell membrane (Bakema and van Egmond, 2014). Cetuximab and panitumumab activate the immune system differently. Cetuximab is a chimeric IgG1 antibody whereas panitumumab is a fully human IgG2 antibody with significantly lower immunogenicity (Mellor et al., 2013). Thus, the combination of cetuximab and monoclonal antibodies targeting CTLA4 and PD-1 antigens is a promising strategy.

The combination of radiotherapy and immunotherapy has also proven feasible. Radiation therapy in SCAC has an immunomodulatory impact (Martin et al., 2017) confirmed by the delayed response observed after the end of treatment. The activation of an immune response with progressive tumor eradication over several weeks could be a plausible explanation for this well known clinical phenomenon (Glynne-Jones et al., 2017).

Over the last few years, numerous preclinical studies have demonstrated that the combination of local irradiation and immunotherapy synergistically induces antitumor immunity (Reynders et al., 2015). Furthermore, an abscopal effect has already been described, i.e. a reduction or disappearance of metastatic deposits following the treatment of the primary tumor mass with radiotherapy. For this reason, we

Table 2

Results from the most important studies on immunotherapy in SCAC.

\begin{tabular}{|c|c|c|c|c|c|c|c|c|c|c|}
\hline & $\begin{array}{l}\text { G3/G4 } \\
\text { adverse } \\
\text { event\% }\end{array}$ & $\begin{array}{l}\text { Treatment- } \\
\text { related death } \%\end{array}$ & $\begin{array}{l}\text { Median time to } \\
\text { response } \\
\text { (months) }\end{array}$ & $\begin{array}{l}\text { Complete } \\
\text { response } \%\end{array}$ & $\begin{array}{l}\text { Partial } \\
\text { response } \%\end{array}$ & $\begin{array}{l}\text { Stable } \\
\text { disease } \%\end{array}$ & $\begin{array}{l}\text { Median PFS } \\
\text { (months) }\end{array}$ & $\begin{array}{l}\text { Median OS } \\
\text { (months) }\end{array}$ & $\begin{array}{l}\text { Six- } \\
\text { month OS } \\
\%\end{array}$ & $\begin{array}{l}\text { One- } \\
\text { year OS } \\
\%\end{array}$ \\
\hline $\begin{array}{c}\text { Ott et al. (pembrolizumab) } \\
\text { (Rogers et al., 2015) }\end{array}$ & 16 & 0 & 3.6 & 0 & 17 & 42 & 3.0 & 9.3 & 64.5 & 47.6 \\
\hline $\begin{array}{l}\text { Morris et al. (nivolumab) } \\
\text { (Nelson, 2017). }\end{array}$ & 13.5 & 0 & 5.8 & 5.4 & 13.5 & 47 & 4.1 & 11.5 & NA & 48 \\
\hline
\end{tabular}

SCAC, squamous cell carcinoma of the anal canal; PFS, progression-free survival; OS, overall survival; NA, not available. 
believe that the combination of irradiation and immunothrapy could determinate a synergistic effect. Currently, there is only one study ongoing to assess the efficacy of nivolumab after combined modality therapy in patients with high-risk stage II-IIIB anal cancer (Anon., 2018).

In this regard, head and neck cancers have been widely investigated and several authors have reported PD-1and tumor infiltrating lymphocyte (TIL) expression in HPV-positive patients which correlates with a better response to chemoradiotherapy and a superior outcome (Badoual et al., 2013; Partlová et al., 2015). Several studies have suggested that PD-1, PD-L1 and CD8 expression and TIL concentration may influence the efficacy of immunotherapy. Furthermore, a recent paper by Balermpas et al. reported a correlation between HPV-16 positivity, PD-1 expression and TIL concentration (Balermpas et al., 2017). In fact, results highlighted a response to immunotherapy in HPV-16-positive patients whose tumors showed high PD-1 and TIL levels. These findings pave the way towards a more rationale development of anti-EGFR plus immunotherapy combinations in SCAC and may justify the use of HPV16 positivity and PD-1, PD-L1 and TIL expression as stratification factors in future studies.

\section{Conclusions}

Although there are high hopes for the combination of radiotherapy and immunotherapy in the treatment of SCAC, several issues remain to be clarified. In addition to identifying the most effective immunotherapeutic drugs, the best combination of radiotherapy and immunotherapy must also be determined. In fact, although radiation leads to the recruitment of immune cells in the tumor, it also induces apoptosis in mature NK cells. Further studies are needed to address these important issues.

Treatment with EGFR inhibitors is also considered a promising approach. Although chemoradiotherapy has shown important treatmentrelated toxicity, the 2 most recent studies reported good efficacy and tolerability to treatment with lower doses of radiotherapy. With regard to advanced disease, interesting results have been obtained with immunotherapy. The association of cetuximab and immunotherapy is also an interesting possibility as the EGFR inhibitor is known to exert an influence on the immune system and may thus increase the efficacy of immunotherapeutic drugs. There is currently no clinical trial ongoing to test this association.

In conclusion, whilst it may be too early to boast of a new era in the treatment of anal carcinoma, a change for the better has begun.

\section{Disclosure}

The authors have no conflicts of interest to declare.

\section{Authors' contributions}

All authors contributed equally to this manuscript and read and approved the final version for submission.

\section{Funding}

No funding.

\section{Acknowledgement}

The authors would like to thank Gráinne Tierney for editorial assistance.

\section{References}

Ajani, J.A., Carrasco, C.H., Jackson, D.E., et al., 1989. Combination of cisplatin plus fluoropyrimidine chemotherapy effective against liver metastases from carcinoma of the anal canal. Am. J. Med. 87, 221-224.

Altekruse, S.F., Kosary, C.L., Krapcho, M., et al., 1975. SEER Cancer Statistics Review 1975-2007. National Cancer Institute Bethesda, NIH, MD.

https://clinicaltrials.gov/ct2/show/NCT03233711.

Badoual, C., Hans, S., Merillon, N., et al., 2013. PD-1-expressing tumor-infiltrating T cells are a favorable prognostic biomarker in HPV-associated head and neck cancer. Cancer Res. 73, 128-138.

Bakema, J.E., van Egmond, M., 2014. Fc receptor-dependent mechanisms of monoclonal antibody therapy of cancer. Curr. Top. Microbiol. Immunol. 382, 373-392.

Balermpas, P., Martin, D., Wieland, U., et al., 2017. Human papilloma virus load and PD1/PD-L1, CD8 and FOXP3 in anal cancer patients treated with chemoradiotherapy: rationale for immunotherapy. OncoImmunology 6 (e1288331).

Barmettler, H., Komminoth, P., Schmid, M., et al., 2012. Efficacy of cetuximab in combination with FOLFIRI in a patient with KRAS wild-type metastatic anal cancer. Case Rep. Oncol. 5, 428-433.

Cacheux, W., Rouleau, E., Briaux, A., et al., 2016. Mutational analysis of anal cancers demonstrates frequent PIK3CA mutations associated with poor outcome after salvage abdominoperineal resection. Br. J. Cancer 114, 1387-1394.

Capelli, L., Casadei Gardini, A., Scarpi, E., et al., 2016. No evidence of NRAS mutation in squamous cell anal carcinoma (SCAC). Sci. Rep. 6, 37621.

Casadei Gardini, A., Capelli, L., Ulivi, P., et al., 2014. KRAS, BRAF and PIK3CA status in squamous cell anal carcinoma (SCAC). PLoS One 9, e92071.

Clark, M.A., Hartley, A., Geh, J.I., 2004. Cancer of the anal canal. Lancet Oncol. 5, $149-157$.

Deutsch, E., Lemanski, C., Pignon, J.P., et al., 2013. Unexpected toxicity of cetuximab combined with conventional chemoradiotherapy in patients with locally advanced anal cancer: results of the UNICANCER ACCORD 16 phase II trial. Ann. Oncol. 24, 2834-2838.

Faivre, C., Rougier, P., Ducreux, M., et al., 1999. 5-fluorouracil and cisplatinum combination chemotherapy for metastatic squamous-cell anal cancer. Bull. Cancer 86, $861-865$.

Gancz, D., Fishelson, Z., 2009. Cancer resistance to complementdependent cytotoxicity (CDC): Problem-oriented research and development. Mol. Immunol. 46, 2794-2800.

Garg, M.K., Zhao, F., Sparano, J.A., et al., 2017. Cetuximab plus chemoradiotherapy in immunocompetent patients with anal carcinoma: a Phase II Eastern Cooperative Oncology Group-American College of Radiology Imaging Network Cancer Research Group Trial (E3205). J. Clin. Oncol. 35, 718-726.

Glynne-Jones, R., Sebag-Montefiore, D., Meadows, H.M., et al., 2017. Best time to assess complete clinical response after chemoradiotherapy in squamous cell carcinoma of the anus (ACT II): a post-hoc analysis of randomised controlled phase 3 trial. Lancet Oncol. 18, 347-356.

Gujja, S., Williamson, S.K., Batra, A., et al., 2015. Programmed cell death-Ligand 1 (PD -L1) expression and outcome in patients with squamous cell cancer of anal canal (SCCAC). J. Clin. Oncol. 33 (abstr 3523).

Jaiyesimi, I.A., Cisplatin, Pazdur R., 1993. 5-fluorouracil as salvage therapy for recurrent metastatic squamous cell carcinoma of the anal canal. Am. J. Clin. Oncol. 16, $536-540$.

Johnson, L.G., Madeleine, M.M., Newcomer, L.M., et al., 2004. Anal cancer incidence and survival: the surveillance, epidemiology, and end results experience, 1973-2000. Cancer 101, 281-288.

Khater, R., Frenay, M., Bourry, J., et al., 1986. Cisplatin plus 5-fluorouracil in the treatment of metastatic anal squamous cell carcinoma: a report of two cases. Cancer Treat. Rep. 70, 1345-1346.

Kim, D.W., Byer, J., Kothari, N., et al., 2017. EGFR inhibitors in patients with advanced squamous cell anal carcinomas: a single-Institution experience. Oncology 92 (4), 190-196.

Leon, O., Guren, M.G., Radu, C., et al., 2015. Phase I study of cetuximab in combination with 5-fluorouracil, mitomycin $\mathrm{C}$ and radiotherapy in patients with locally advanced anal cancer. Eur. J. Cancer 51, 2740-2746.

Lukan, N., Ströbel, P., Willer, A., et al., 2009. Cetuximab-based treatment of metastatic anal cancer: correlation of response with KRAS mutational status. Oncology 77, 293-299.

Martin, D., Rödel, F., Balermpas, P., et al., 2017. The immune microenvironment and HPV in anal cancer: rationale to complement chemoradiation with immunotherapy. Biochim. Biophys. Acta 1868, 221-230.

Mellor, J.D., Brown, M.P., Irving, H.R., et al., 2013. A critical review of the role of Fc gamma receptor polymorphisms in the response to monoclonal antibodies in cancer. J. Hematol. Oncol. 6, 1.

Morris, V.K., Salem, M.E., Nimeiri, H., et al., 2017. Nivolumab for previously treated unresectable metastatic anal cancer (NCI9673): a multicentre, single-arm, phase 2 study. Lancet Oncol. 18, 446-453.

Nelson, V.M., Benson 3rd, A.B., 2017. Epidemiology of anal canal cancer. Surg. Oncol. Clin. N. Am. 26, 9-15.

Nigro, N.D., Vaitkevicius, V.K., Considine, B., 1974. Combined therapy for cancer of the anal canal: a preliminary report. Dis. Colon Rectum 17, 354-356.

Olivatto, L.O., Vieira, F.M., Pereira, B.V., et al., 2013. Phase 1 study of cetuximab in combination with 5-fluorouracil, cisplatin, and radiotherapy in patients with locally advanced anal canal carcinoma. Cancer 119, 2973-2980.

Ott, P.A., Piha-Paul, S.A., Munster, P., et al., 2017. Safety and antitumor activity of the anti-PD-1 antibody pembrolizumab in patients with recurrent carcinoma of the anal canal. Ann. Oncol. 28, 1036-1041.

Partlová, S., Bouček, J., Kloudová, K., et al., 2015. Distinct patterns of intratumoral immune cell infiltrates in patients with HPV-associated compared to non-virally induced head and neck squamous cell carcinoma. Oncoimmunology 4, e965570.

Reynders, K., Illidge, T., Siva, S., et al., 2015. The abscopal effect of local radiotherapy: using immunotherapy to make a rare event clinically relevant. Cancer Treat. Rev. 41 
(June (6)), 503-510.

Rogers, J.E., Silva, N.N., Eng, C., et al., 2015. Cetuximab in combination with cisplatin and 5-fluorouracil induces dramatic response in metastatic refractory squamous cell carcinoma of the anal canal. J. Gastrointest. Oncol. 6, E82-85.

Rogers, J.E., Ohinata, A., Silva, N.N., et al., 2016. Epidermal growth factor receptor inhibition in metastatic anal cancer. Anticancer Drugs 27, 804-808.

Sparano, J., Lee, J., Palefsky, J., et al., 2017. Cetuximab plus chemoradiotherapy for HIVassociated anal carcinoma: a phase II AIDS malignancy consortium trial. J. Clin.
Oncol. 35 (7), 727-733.

Tanum, G., 1993. Treatment of relapsing anal carcinoma. Acta Oncol, 32, 33-35. Yanik, E.L., Kaunitz, G.J., Cottrell, T.R., et al., 2017. Association of HIV status with local immune response to anal squamous cell carcinoma: implications for immunotherapy. JAMA Oncol 3 (July (7)), 974-978.

Zampino, M.G., Magni, E., Sonzogni, A., Renne, G., et al., 2009. K-ras status in squamous cell anal carcinoma (SCC): it's time for target-oriented treatment. Cancer Chemother. Pharmacol. 65, 197-199. 